\title{
Capsule Commentary on Weng et al., Assessing the Quality of Osteoporosis Care in Practice
}

\author{
Elizabeth R. Pfoh, PhD, MPH \\ Division of General Internal Medicine, Johns Hopkins School of Medicine, Baltimore, MD, USA.
}

J Gen Intern Med 30(11):1702

DOI: $10.1007 / \mathrm{s} 11606-015-3376-5$

(c) Society of General Internal Medicine 2015

$\mathrm{W}$ eng and colleagues developed a composite quality measure for osteoporosis care from eight individual, evidence-based performance measures. ${ }^{1}$ The composite measure represents a weighted sum of the eight measures, with the weights decided upon by an expert panel. The expert panel also identified thresholds for competent and excellent care. Measure performance was evaluated using data from chart reviews submitted by 381 physicians - with each physician submitting approximately 25 charts - as part of the American Board of Internal Medicine (ABIM) Osteoporosis Practice Improvement Module $^{\circledR}$ (PIM). Eight-four percent and $22 \%$ of physicians met the standard for competent and excellent care on the composite measure, respectively.

Quality of care indicators are being applied through federal policy programs such as Meaningful $\mathrm{Use}^{2}$ and Physician Quality Reporting ${ }^{3}$, which have incentives and penalties associated with meeting benchmarks. By 2018 the goal is to have $50 \%$ of all Medicare payments tied to quality or value. ${ }^{4}$ Therefore, developing appropriate measures of care quality and understanding any discrepancy in how different specialties perform are important. In the current study, rheumatologists and endocrinologists were more likely to meet the standard for excellent care compared to generalists. These physicians are more likely to focus on osteoporosis care. Similarly, a study by Edwards and colleagues ${ }^{5}$ found that cardiologists were more likely to meet cardiovascular quality measures than generalists. Taken together, these studies raise the issue of whether specialists deliver higher quality diseasespecific care. Conversely, there may be legitimate reasons why generalists perform worse on disease-specific measures. Whether generalists should be held to the same diseasespecific performance standards as specialists is an important discussion, especially when the goal is to incentivize the best care possible for patients.

Conflict of Interest: The author has no conflicts of interest with this article.

Corresponding Author: Elizabeth R. Pfoh, $\mathrm{PhD}, \mathrm{MPH}$; Division of General Internal Medicine, Johns Hopkins School of Medicine, Baltimore, MD 21287, USA (e-mail: epfoh1@jhu.edu).

\section{REFERENCES}

1. Weng W, Hess BJ, Lynn LA, Lipner RS. Assessing the quality of osteoporosis care in practice. J Gen Intern Med. doi:10.1007/s1 1606-015-3342-2.

2. Centers for Medicare and Medicaid Services. EHR Incentive Programs: The Official Web Site for the Medicare and Medicaid Electronic Health Records (EHR) Incentive Programs. Available at: http://www.cms.gov/Regulationsand-Guidance/Legislation/EHRIncentivePrograms/index.html?redirect=/ ehrincentiveprograms/. Accessed 14 Apr 2015

3. American Medical Association. 2015 Physician Quality Reporting System. Available at: http://www.ama-assn.org/ama/pub/physician-resources/ clinical-practice-improvement/clinical-quality/physician-quality-reportingsystem.page?. Accessed 14 Apr 2015

4. Burwell SM. Setting value-based payment goals-HHS efforts to improve US health care. N Engl J Med. 2015;372(10):897-9.

5. Edwards ST, Mafi JN, Landon BE. Trends and quality of care in outpatient visits to generalist and specialist physicians delivering primary care in the United States, 1997-2010. J Gen Intern Med. 2014;29(6):947-55. 